\title{
EFEKTIVITAS MODEL PEMBELAJARAN BERBASIS KOMPETENSI DENGAN PENDEKATAN DUNIA KERJA PADA PROGRAM D3 TATA BOGA
}

\author{
Rina Febriana \\ Fakultas Teknik Universitas Negeri Jakarta \\ email: rinafebriana@unj.ac.id
}

\begin{abstract}
Abstrak: Penelitian bertujuan untuk menghasilkan model pembelajaran berbasis kompetensi dengan pendekatan dunia kerja (model PKBK), rumusan kompetensi mahasiswa D3 Tata Boga, rancangan pembelajaran berbasis kompetensi, dan rubrik penilaian. Penelitian ini merupakan penelitian dan pengembangan yang mengadopsi model prosedural Borg \& Gall.Subjek penelitian adalah praktisi industri perhotelan, mahasiswa proram D3 Tata Boga dan dosen matakuliah praktik. Teknik pengumpulan data lewat FGD dan pemberian angket, sedang teknik analisis data dilakukan secara deskriptif kualitatitif dan statistik deskriptif. Hasil penelitian ini adalah (1) model PKBK memiliki komponen: profil lulusan, learning outcomes, rumusan kompetensi, pengalaman pembelajaran, rancangan pembelajaran, dan evaluasi kompetensi, (2) rumusan kompetensi untuk lulusan terbagi menjadi 2 kelompok yaitu technical skills dan employability skills, (3) rancangan pembelajaran pada model PKBK terdiri dari: struktur kurikulum, materi dan bahan pembelajaran, diagram pencapaian kompetensi dan dokumen kurikulum, (4) rubrik penilaian berisi penilaian terhadap employability dan technical skills.
\end{abstract}

Kata Kunci: Efektivitas, pembelajaran berbasis kompetensi, dunia kerja, D3 Tata Boga

\section{THE EFFECTIVENESS OF A COMPETENCY-BASED LEARNING MODEL USING WORLD OF WORK APPROACH AT D3 FOOD AND NUTRITION PROGRAMME}

\begin{abstract}
This research aims to produce a model of competence-based learning using the world of work approach (model PKBK), to formulate students' competence, to design competence-based learning, and to develop evaluation rubric. This research adopted Research and Development model developed by Borg and Gall. The research subjects were hotel practitioners, students of D3 Food and Nutrition, and lechturers of practice courses. Data were collected through FGDs and questionnaires and analysed using descriptive qualitative and descriptive stastitics tecniques. The findings show that (1) the PKBK model comprises graduates' profile, learning outcomes, competence formulation, learning design, and competence evaluation; (2) the graduates' competence can be categorized into technical skills dan employability skills,(3) PKBK learning model consists of curriculum structure, learning material, diagram of competence achievement and curriculum documentation, (4) evaluation rubric comprises evaluation on employability dan technical skills.
\end{abstract}

Keywords : effectiveness, competency-based learning, the world of work, D3 Food and Nutrition

\section{PENDAHULUAN}

Kemendiknas dalam hal ini Dikti memunculkan isu-isu strategis berkaitan dengan dunia kerja dan dunia pendidikan. Isu-isu tersebut antara lain sebagai berikut. (1) Rancang bangun pendidikan tinggi belum selaras dengan dunia kerja, termasuk alternatif model pendidikan tinggi yang mampu menghasilkan lulusan yang profesional dan berjiwa wirausaha. (2) Kurangnya sinergitas antara lembaga dalam penyiapan lulusan sesuai kebutuhan tenaga kerja. (3) Kurikulum yang diharapkan mampu menghasilkan lulusan yang memiliki kualifikasi dan kompetensi. Lemahnya kemitraan pemerintah, lembaga diklat dalam pemberdayaan masyarakat untuk memberikan kontribusi pengembangan ekonomi. (4) Kurangnya pusat unggulan berbasis riset. (5) Kurangnya keselarasan hasil penelitian PT dengan kebutuhan masyarakat. (6) Belum optimalnya keterlibatan dunia usaha dalam kegiatan penelitian di perguruan tinggi. 
Dasar pendidikan kejuruan telah dikemukakan berbagai pakar, antara lain Lynch (2000), Finch \& Crunkilton (1999) serta Thompson (1973) yang pada dasarnya sama, yaitu bahwa pendidikan kejuruan adalah bagian dari sistem pendidikan yang mempersiapkan seseorang agar menjadi manusia produktif dan mampu bekerja pada bidang pekerjaan tertentu yang sesuai dengan bakat, minat, dan keterampilan yang telah dikembangkan pada proses pendidikan.

Lulusan Diploma Tiga (D3) Tata Boga diarahkan untuk memiliki kemampuan dalam perencanaan hidangan dan menu, pengolahan dan penyajian makanan, perhitungan food cost dan harga jual, sebagai laboran, pelaksana maupun pengawas dalam bidang jasa boga, serta melaksanakan dan mengelola usaha boga. Hasilpenelitian Sachriani (2008) menunjukan bahwa hanya $31,3 \%$ alumni yang diterima bekerja di industri sebagai juru masak (cook), dan 71,6\% responden menyatakan bahwa prospek jenis karier sangat terbatas.

Pembelajaran yang dilakukan saat ini sebagian besar berbentuk penyampaian secara tatap muka (lecturing), searah, lebih bersifat Teacher Centered Learning (TCL). Pada saat mengikuti perkuliah yang bersifat teori maupun praktik, mahasiswa cenderung mendengarkan ceramah, mahasiswa kesulitan menangkap makna esensi materi pembelajaran. Kondisi pembelajaran dosen aktif dan makasiswa pasif ini efektivitasnya rendah, dan tidak dapat menumbuhkembangkan proses partisipasi aktif mahasiswa dalam pembelajaran. Dosen menjadi pusat peran dalam pencapaian hasil pembelajaran dan pencapaian kompetensi. Dengan demikian pola pembelajaran yang terpusat pada dosen seperti yang dipraktikkan saat ini kurang memadai untuk mencapai tujuan pendidikan berbasis kompetensi. Dari beberapa penjelasan di atas, peneliti bermaksud mengembangkan model pembelajaran berbasis kompetensi pada Program Diploma 3 Tata Boga dengan pendekatan dunia kerja.

Selain tuntutan keterampilan dasar dan keterampilan dalam bidang yang ditekuni, dunia kerja menghendaki keterampilan employabilitas calon tenaga kerja. Keterampilan employabilitas (employability skills) adalah kemampuan mengelola keterampilan sikap dan perilaku bekerja seperti yang diharapkan oleh pihak industri/ dunia kerja (Leish, 2002). Kompetensi dalam dunia kerja dimaknai sebagai aspek-apek pribadi (LO-
MAS, 1998).Aspek-aspek pribadi ini termasuk sifat, motif-motif, sistem nilai, sikap, pengetahuan, dan keterampilan.

Temuan ini selaras dengan kajian yang dilakukan Samani (2004) yang menemukan urutan kompetensi utama yang dibutuhkan industri yang meliputi jujur, disiplin, tanggungjawab, kerjasama, memecahkan masalah, dan penguasaan bidang kerja. Selaras dengan hal tersebut, penelitian terbaru yang dilakukan Andreas (Samani, 2004) menunjukkan bahawa kompetensi utama yang diharapkan industri meliputi urutan jujur, disiplin, komunikasi, kerjasama, dan penguasaan bidang studi.

Dalam penelitiannya, Widiyanto (2011) menyimpulkan bahwa kebutuhan kompetensi Du/Di meliputi pengetahuan (knowledge), kemampuan keahlian (skill), perilaku (attitude), dan lainnya (others) seperti pengalaman. Selain itu hasil temuan dilapangan (Widiyanto:2011) dapat dirinci sebagai berikut: (1) pengetahuan (knowledge) yang meliputi: pengetahuan sesuai dengan bidang, nilai akademik, pengetahuan umum, pengetahuan usaha, (2) keahlian (skill) yang mencakup: kemampuan, keterampilan, cekatan, kreativitas, (3) perilaku (attitude) terdiri atas: etika, motif, integritas (percaya diri), komunikasi, dan (4) lain-lain (others) yang termasuk didalamnya pengalaman, kemampuan tambahan lain, dan hobi.

Secara umum persyaratan kompetensi yang dibutuhkan dunia kerja dibagi dalam dua kelompok besar, yaitu technical skills dan employability skills. Technical skills atau kemampuan teknis adalah kemampuan pada bidang pekerjaan yang meliputi pengetahuan dan keterampilan, sedangan employability skills adalah kemampuan mengelola keterampilan sikap dan perilaku bekerja, yang meliput attitude dan pengetahuan terhadap sifat pekerjaan.

The Secretary's Commision on Achieving Necessary Skills (SCANS) melakukan kajian untuk mengidentifikasi dan menguraikan keterampilan yang diperlukan di tempat kerja (Kane, 1990). Pada awalnya SCANS menemukan tujuh keterampilan fungsional yaitu keterampilan yang penting bagi seorang pekerja, yakni resource management, information management, social interaction, systems behaviour and performance, human and technology interaction, and afective skills. Berdasarkan review dan verifikasi yang mendalam, SCANS membuat dua kelompok 
keterampilan, yakni keterampilan dasar dan kompetensi di tempat kerja, seperti ditunjukkan pada Tabel 1.

Tabel 1. Keterampilan SCANS

\begin{tabular}{ccl}
\hline Foundation & 1. & Basic Skills \\
Skills & 2. & Thinking Skills \\
& 3. & Personal Qualities \\
\hline Workplace & 4. & Resources \\
Competencies & 5. & Interpersonal \\
& 6. & Information \\
& 7. & Systems \\
& 8. & Technology \\
\hline
\end{tabular}

Sumber: SCANS2000 Center, Jhons Hopkins University, 2001.

The Conference Board of Canada juga telah mengembangkan profil keterampilan employabilitas sebagai alat untuk membantu para pendidik dalam rangka menyiapkan lulusannya memasuki dunia kerja. Profil tersebut, diperbaharui pada bulan Mei 2000, sebagai refleksi terhadap tuntutan pekerjaan di era globalisasi, yang kemudian dikenal dengan istilah Employability Skills 2000+. Kerangka Employability Skills 2000+ terdiri dari employability skills, attitudes and behaviour, seperti ditujukan pada Tabel 2.
Tabel 2. Keterampilan Employabilitas 2000+, Kanada

\begin{tabular}{cll}
\hline Fundamental & 1. Communication \\
Skills & 2. Manage information \\
& 3. Use numbers \\
& 4. Think and solve problems \\
\hline Personal & 5. Demontrate positive attitudes \\
Management & & and behaviours \\
Skills & 6. Be responsible \\
& 7. Be Adaptable \\
& 8. Learn Continuously \\
& 9. Work Safety \\
\hline Teamwork & 10. Work with others \\
Skills & 11. Participate in Projects \\
& and Task \\
\hline
\end{tabular}

Sumber: The Conference Board of Canada, 2000.

\section{Model Pembelajaran Berbasis Kompetensi dengan Pendekatan Dunia Kerja}

Pendekatan pembelajaran berbasis kompetensi dilakukan melalui pembelajaran yang berpusat kepada mahasiswa, Student Centered Learning (SCL). Mahasiswa ditempatkan sebagai subyek belajar. Pendekatan berbasis kompetensi harus memperhatikan peta pencapaian kompetensi suatu bidang atauprogram keahlian.Apakah suatu unit kompetensi memerlukan pre-requisites atau sebagai pre-requisites bagi kompetensi berikutnya. Peta ini harus jelas struktur dan bangunannya

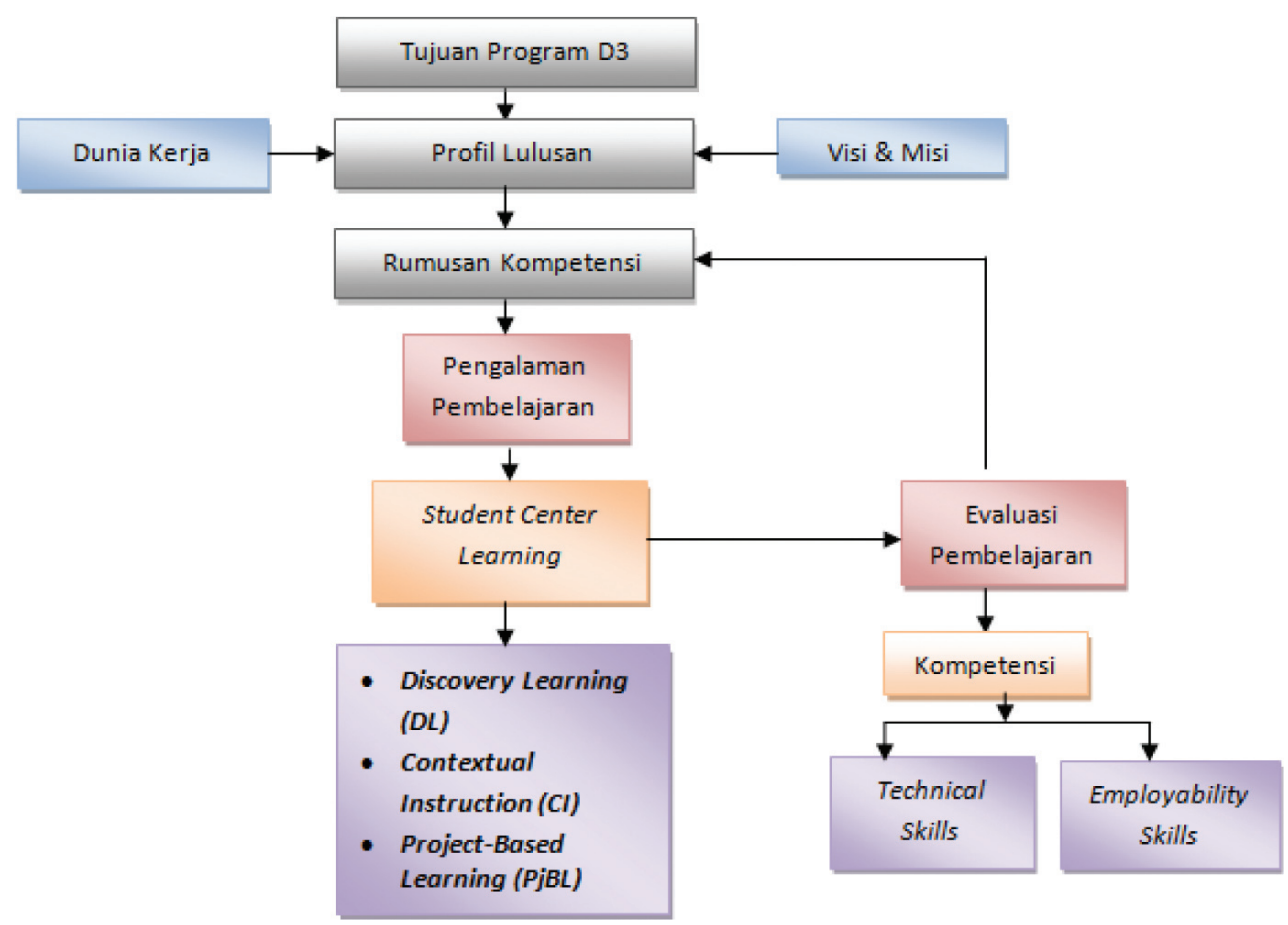

Gambar 1.

Model Konseptual Pembelajaran Berbasis Kompetetensi dengan Pendekatan Dunia Kerja 
sebagai acuan pelaksanaan diklat kompetensi. Dosen bersama mahasiswa dapat membuat program perencanaan penyelesaian unit-unit kompetensi secara terprogram. Ini akan membangun attitude mahasiswa untuk bertanggungjawab atas kemajuan dirinya. Untuk mendukung pencapaian kompetensi, dosen bersama sekolah menyediakan dan memfasilitasi setiap mahasiswa untuk belajar kapan dan dimana saja.

\section{METODE}

Penelitian inimenggunakan metode penelitian dan pengembangan dengan mengadopsi model Borg and Gall (1989). Subjek penelitian adalah praktisi industri perhotelan, mahasiswa program D3 Tata Boga dan dosen matakuliah praktik.

Analisis kebutuhan dimulai dengan analisis kompetensi berdasarkan Kerangka Kualifikasi Nasional Indonesia (KKNI), wawancara dengan praktisi perhotelan untuk memperoleh informasi kompetensi yang dibutuhkan industri, permasalahan-permasalahan yang berkaitan dengan kompetensi, serta trend dan prospek karir ke depan. Selain itu, dilakukan prasurvei pada program studi D3 Tata Boga untuk mendapatkan data tentang kurikulum D3 Tata Boga yang berlaku saat ini sebagai bahan dan data untuk menyusun model konseptual dalam pengembangan kurikulum.

Model konseptual yang telah dirancang selanjutnya dibahas dalam Focus Group Discussion (FGD) yang melibatkan praktisi industri (4 orang), asosiasi profesi (1 orang), dan akademisi (3 orang). Tujuan dari FGD adalah untuk mendapatkan kesepakatan mengenai model yang diajukan. Hasil FGD divalidasi dengan menggunakan teknik Delphi yang melibatkan empat orang ahli kurikulum dengan tujuan untuk mendapatkan masukan terkait dengan model hipotetik yang sudah dirumuskan. Validasi dengan teknik Delphi ini dimaksudkan untuk mendapatkan komentar dan penilaian mengenai produk yang akan diuji coba dengan 4 kriteria: (1) dapat diterapkan; (2) dapat diterapkan dengan revisi kecil; (3) dapat diterapkan dengan revisi besar; dan (4) belum dapat diterapkan (Skulmoski, 2007).

Selain memvalidasi model hipotetik ini, ini para ahli diberikan lima jenis instrumen, yakni: (1) lembar penilaian panduan pengembangan, (2) lembar validasi panduan model, (3) lembar rubrik pencapaian kompetensi, (4) lembar penilaian keterlaksanaan model, (5) lembar penilaian efektivitas model.

Kepraktisan dari produk dikatakan tercapai jika PKBK yang dikembangkan dapat diterapkan dengan hasil penilaian keterlaksanaan model menunjukkan kategori dapat diterapkan. Keefektifan PKBK dikatakan efektif jika penilaian model oleh responden berada pada skor $>$ 3,0. Tahapan penelitian dalam bentuk fish bone ditunjukkan pada Gambar 2.

Data yang diperoleh dianalisis secara deskriptif kualitatif dan statistik deskriptif.

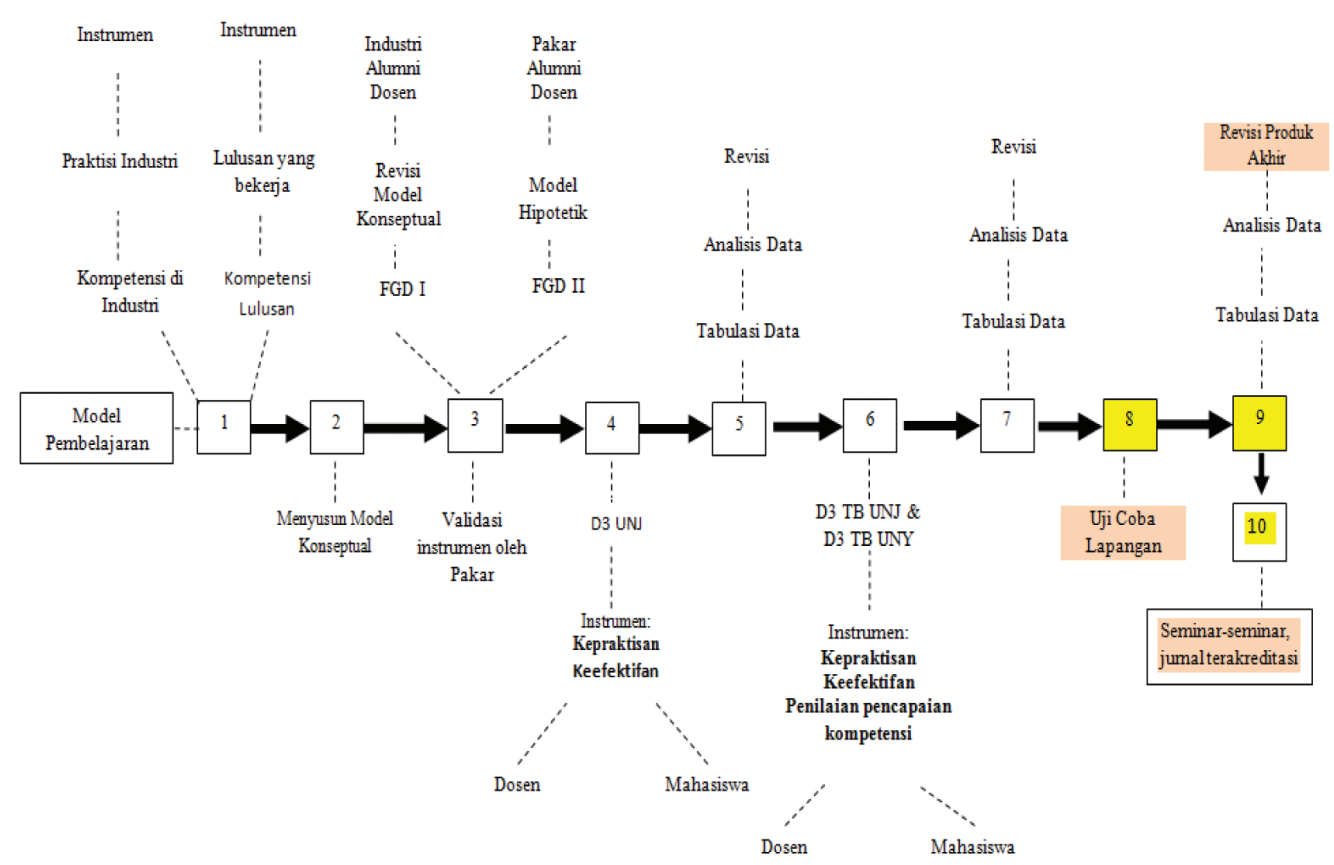

Gambar 2. Tahapan Penelitian 


\section{HASIL DAN PEMBAHASAN Penelitian dan Pengumpulan Informasi}

Hasil studi pendahuluan menunjukkan bahwa bidang pekerjaan yang didominasi oleh lulusan D3 Tata boga adalah bekerja pada industri perhotelan, catering,dan wiraswata. Hasil penelitian Sachriani (2008) menunjukan bahwa hanya $31,3 \%$ alumni yang diterima bekerja di industri sebagai juru masak (cook), dan 71,6\% alumni menyatakan bahwa prospek jenis karier sangat terbatas. Pemetaan kompetensi pada program D3 dilakukan dengan kegiatan prasurvei, yang meliputi, wawancara, dan penyebaran kuesioner pada praktisi industri. Berdasarkan hasil kegiatan tersebut teridentifikasi sejumlah kompetensi yang dibutuhkan dunia kerja. Hasil analisis terhadap angket yang direspons oleh para narasumber tersebut, maka diperoleh elemen kompetensi yang dibutuhkan oleh dunia kerja yang mengacu pada pekerjaan yang berlaku di dunia kerja. Hasil identifikasi tersebut, kemudian disusun dalam matriks kompetensi kebutuhan dunia kerja. Secara garis besar kompetensi ini terdiri dari 2 kompetensi utama, yaitu (1) technical skills dan (2) employability skillss. Kedua komponen utama tersebut akan dikembangkan dalam evaluasi kurikulum. Masing-masing komponen akan dijabarkan lebih rinci menjadi indikator-indikator pada Tabel 3.

Dari data kompetensi yang dibutuhkan dunia kerja ternyata ditemukan fakta bahwa dunia kerja lebih mengutamakan employability skills daripada technical skills. Alasannya adalah bahwa dengan memiliki employability skills yang tinggi para lulusan dapat dengan mudah beradaptasi dengan lingkungan kerja, lebih mandiri, bertanggungjawab dan lebih mudah untuk diarahkan menjadi seorang professional yang baik. Selain itu dari hasil angket diperoleh alasan bahwa lulusan yang memiliki kemampuan employabilitas yang tinggi akan lebih mudah mengembangkan diri dalam karir dan lebih siap dalam bekerja.

Hasil penelitian Arfandi (2013) tentang technical skills yang dibutuhkan industri menyatakan bahwa 47,37\% technical skills masih sangat dibutuhkan oleh industri, namun masih terdapat $11,28 \%$ technical skills yang tidak dibutuhkan lagi bahkan $1,5 \%$ sangat tidak dibutuhkan lagi. Sementara itu keterampilan bekerja (employability skills) 58,21 lebih cenderung kepada aspek komunikasi, inisiatif dan keberanian usaha, serta kemampuan untuk bekerja sama secara tim.

\section{Pengembangan Rancangan Produk Awal}

Pada tahap ini dihasilkan instrumen yang sudah divalidasi melalui expert judgement. Validasi instrumen bertujuan untuk melihat apakah instrumen yang dikembangkan dalam penelitian ini layak digunakan dan dapat mengukur apayang seharusnya diukur. Dalam validasi instrumen, validator memberikan penilaian dan mengevaluasi atau memberikan masukan untuk menyempurnakan instrumen. Ringkasan hasil penilaian validator terhadap instrumen dapat dilihat pada Tabel 4.

Tabel 3. Kompetensi yang Dibutuhkan Dunia Kerja

\begin{tabular}{lll}
\hline \multicolumn{1}{c}{ Profesi } & \multicolumn{1}{c}{ Kompetensi } & \multicolumn{1}{c}{ Technical skills } \\
& \multicolumn{1}{c}{ Employability Skill } \\
\hline Teknisi BogaProfesional & Mengetahui bidang perkerjaan & Komunikasi \\
(Cook, Captain waiter, Captain & Merencanakan variasi menu & Kerja tim \\
F\&B, Captain/Chief Baker, & Menghitung kebutuhan bahan makanan \& & Pemecahan masalah \\
Assistent Chief Steward, & minuman & Manajemen diri \\
Assistant Chef De Partie, & Mengolah makanan dan minuman & Inisiatif \\
Assisten Pastry Chef, & Menata dan menyajikan makanan \& minuman & Disiplin \\
Bartender) & Memilih metode/alat pengolahan & Jujur \\
& Melaksanakan Standar Operasional Prosedur & \\
& (SOP) & Bertanggungjawab \\
& Melaksanakan prinsip-prinsip manajeman & \\
& POAC) & \\
& Mengawasi dan mengevaluasi pekerjaan & \\
Supervisor di industry jasaboga & Merawat/maintenance alat pengolahan & \\
& Menggunakan ICT dalam bidang kebogaan & \\
& Melaksanakan K3 (keamanan, keselamatan, dan & \\
& ketertiban) & \\
\hline
\end{tabular}


Tabel 4. Ringkasan Data Penilaian Instrumen oleh Validator

\begin{tabular}{|c|c|c|c|c|c|c|}
\hline \multirow[t]{2}{*}{ Aspek yang Dinilai } & \multicolumn{6}{|c|}{ Rata-Rata Penilaian oleh Validator } \\
\hline & Inst. A & Inst. B & Inst. $\mathrm{C}$ & Inst. D & Inst. E & Inst. $\mathrm{F}$ \\
\hline $\begin{array}{l}\text { Petunjuk pengisian lembar validasi dinyatakan } \\
\text { dengan jelas }\end{array}$ & 1 & 1 & 0,75 & 1 & 1 & 0,75 \\
\hline Kriteria penilaian dinyatakan dengan jelas. & 0,75 & 1 & 0,75 & 0,75 & 0,75 & 1 \\
\hline $\begin{array}{l}\text { Tujuan penggunaan lembar validasi dirumuskan } \\
\text { dengan jelas dan terukur. }\end{array}$ & 1 & 0,75 & 1 & 1 & 1 & 1 \\
\hline $\begin{array}{l}\text { Aspek yang diukur dengan lembar validasi sudah } \\
\text { mencakup teori pendukung dan komponen- } \\
\text { komponen model. }\end{array}$ & 0,75 & 0,75 & 0,75 & 1 & 0,75 & 1 \\
\hline $\begin{array}{l}\text { Butir-butir yang dinyatakan untuk setiap aspek } \\
\text { penilaian pada lembar validasi sesuai dengan } \\
\text { tujuan pengukuran. }\end{array}$ & 1 & 1 & 0,75 & 1 & 1 & 0,75 \\
\hline $\begin{array}{l}\text { Rumusan butir-butir aspek penilaian pada lembar } \\
\text { validasi menggunakan kata pernyataan/perintah } \\
\text { yang menuntut pemberian nilai. }\end{array}$ & 1 & 0,75 & 0,75 & 1 & 0,75 & 1 \\
\hline $\begin{array}{l}\text { Rumusan aspek dan butir-butir aspek penilaian } \\
\text { pada lembar validasi menggunakan bahasa } \\
\text { Indonesia yang benar, sederhana, komunikatif, } \\
\text { dan mudah dipahami. }\end{array}$ & 1 & 0,75 & 0,75 & 0,75 & 1 & 0,75 \\
\hline $\begin{array}{l}\text { Rumusan aspek dan butir-butir aspek penilaian } \\
\text { pada lembar validasi tidak menggunakan kata-kata } \\
\text { atau kalimat yang menimbulkan penafsiran ganda. }\end{array}$ & 1 & 0,75 & 0,50 & 1 & 0,75 & 0,75 \\
\hline
\end{tabular}

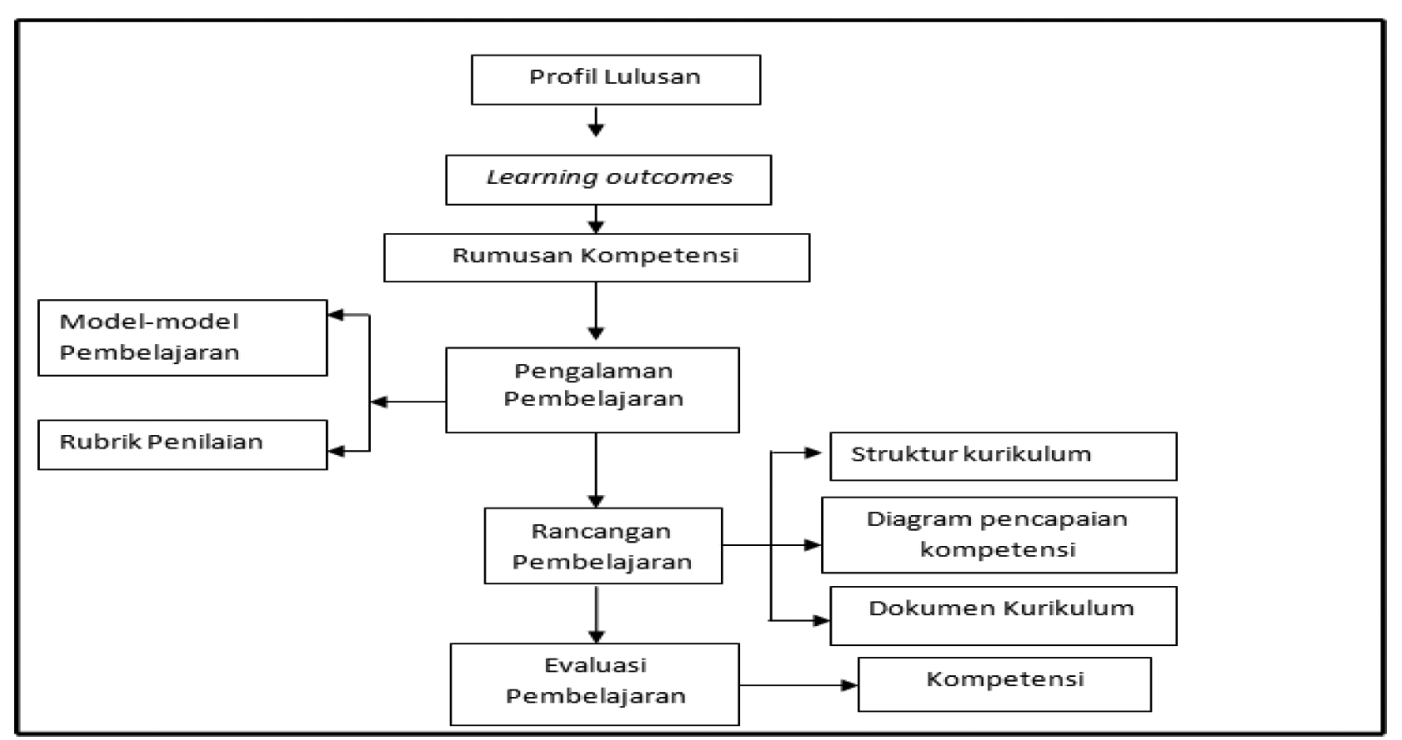

Gambar 3. Model Hipotetik

Berdasarkan pada Tabel 4 di atas, secara umum dapat dilihat bahwa hasil penilaian oleh validator berada pada kriteria baik. Kriteria lembar penilaian dikatakan reliable jika nilai reliabilitasnya $(\mathrm{R}) \geq 0,60$ (Sugiono).

\section{Evaluasi dan Validasi Model dalam FGD}

Model konseptual yang telah divalidasi melalui kegiatan FGD menghasilkan model hipotetik. Gambar 3 adalah model hipotetik hasil validasi FGD.
Model Hipotetik yang dikembangkan dalam penelitian ini dikonsultasikan kembali dan didiskusikan kepada beberapa pakar yang mewakili bidang kurikulum dan pembelajaran di bidang tata boga. Evaluasi model ini bertujuan untuk menyempurnakan tahapan-tahapan pembelajaran dalam model yang dikembangkan sehingga tujuan pengembangan model tercapai dan dapat berjalan efektif. 


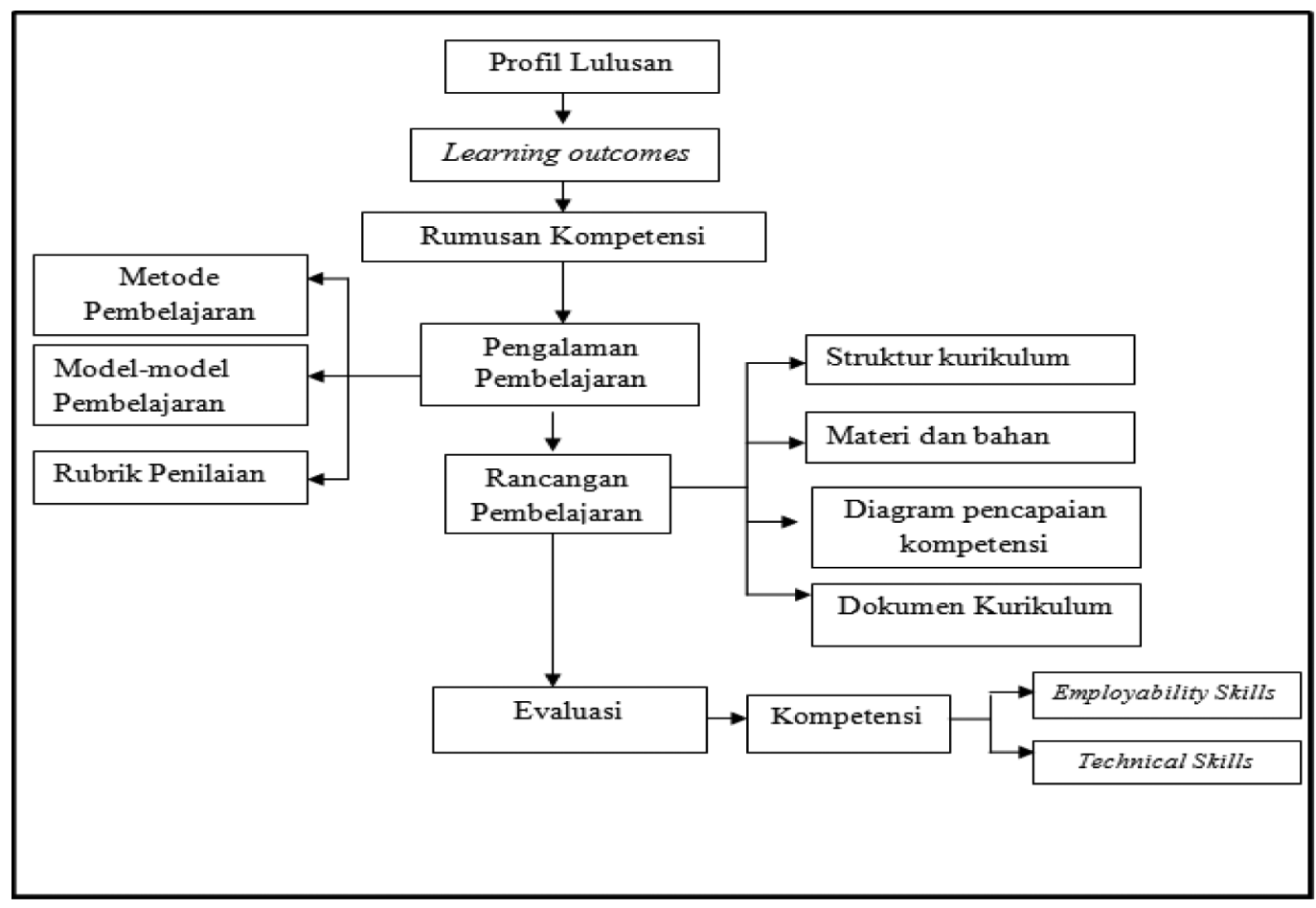

Gambar 4. Model Empirik PKBK

\section{Model Empirik PKBK}

Dari data-data yang diuraikan di atas, berdasarkan hasil FGD dan evaluasi oleh expert judgment diperoleh model empirik PKBK dengan beberapa catatan penting hasil evaluasi adalah: (1) perlu adanya pengelompokkan kurikulum pada struktur kurikulum; (2) menata pencapaian kompetensi pada tiap jenjang semester; (3) pada pengalaman belajar tidak hanya dicantumkan pendekatannya saja tapi juga model-model pembelajaran yang sesuai untuk PKBK; (4) pada proses evaluasi perlu diuraikan komponen kompetensi apa saja yang akan dievaluasi. Model empirik PKBK ditunjukkan pada Gambar 4.

Sofyan (2011) mengemukakan bahwa pembelajaran harus diselenggarakan dengan pengalaman nyata dan otentik, isi pembelajaran harus didesain agar relevan dengan karakteristik siswa, dan harus tersedia media dan sumber belajar yang dibutuhkan agar partisipasi siswa dalam pembelajaran maksimal.

\section{SIMPULAN}

Berdasarkan hasil penelitian dan pengembangan yang dilakukan maka dapat disimpulkan sebagai berikut. Pertama, model pembelajaran berbasis kompetensi dengan pendekatan dunia kerja (PKBK) yang dihasilkan memiliki komponen profil lulusan, learning outcomes, rumusan kompetensi, pengalaman pembelajaran, rancangan pembelajaran, dan evaluasi kompetensi. Kedua, rumusan kompetensi untuk lulusan mahasiswa D3 Tata boga berdasarkan kebutuhan industri terbagi menjadi 2 kelompok yaitu technical skills dan employability skills. Ketiga, rancangan pembelajaran pada model PKBK terdiri dari: struktur kurikulum, materi dan bahan pembelajaran, diagram pencapaian kompetensi dan dokumen kurikulum. Keempat, rubrik penilaian pada model PKBK berisi penilaian terhadap kompetensi employability skills dan technical skills.

\section{UCAPAN TERIMA KASIH}

Ucapan terima kasih disampaikan kepada semua pihak yang telah membantu terlaksananya penelitian ini terutama para narasumber, validator, peserta FGD, dan lain-lain.

\section{DAFTAR PUSTAKA}

Arfandi, Anas. 2013. Relevansi Kompetensi Lulusan Diploma Tiga Teknik Sipil di Dunia Kerja. Jurnal Pendidikan Vokasi. Vol. 3, No. 3, hlm.283-292.

Borg, W.R., \& Gall, M.D. 1989. Educational Research: An Introduction Fourth Edition. New York. Longman. 
Finch, C.R., \& Crunkilton, J.R. 1979. Curriculum development in vocational and technical education: Planning, content and implementation. Boston. Massachusetts: Allyn \& Bacon, Inc.

Kane, M. 1990. The Secretary's Commision on Achieving Necessary Skills (SCANS): Identifying and Describing The Skills Required by Work. Washington, D.C.: Pelavin Associates, Inc.

Kane, M. 1990. The Secretary's Commision on Achieving Necessary Skills (SCANS): Identifying and Describing The Skills Required by Work. Washington, D.C.: Pelavin Associates, Inc.

Leish Mc, A. 2002. Employability Skills for Australian Small and Medium Sized Enterprises: Report of the interviews and focus groups with small and medium enterprises. Department of Education, Science and Training.

LOMA,s Competency Dictionary, 1988. in Hitt, Michael A., R. Edward Freeman and Jeefrey S. Harrison 2006. The Blackwell Handbook of Strategic Management; Print Publication: 2006.

Lynch, R. L. 2000. High School Career and Technical Education for the First Decade of the $21^{\text {st }}$ Century. Journal of Vocatinal Education Research, 25 (2).Diakses pada tanggal 5 Februari 2005 dan http://scholar. Lib.vt.edu/ejournals/JVER/v25n2/Lynch. Html.

Samani, Muchlas. 2004. "Pendidikan kecakapan hidup: Upaya merekonstruksi pendidikan.
Makalah.Disajikan dalam seminar dan lokakarya bidang peningkatan relevansi program DUE-LIKE", Jurusan Pendidikan Fisika IKIP Negeri Singaraja tanggal 15-16 Agustus, di Singaraja.

Sachriani. 2008. Studi Penelusuran Alumni D3 Tata Boga Universitas Negeri Jakarta. Penelitian tidak diterbitkan.

SCANS.2001. About SCANS. Baltimore, Maryland: SCANS2000 Center, Jhons Hopkins University. http://www.scans.wpmc.jhu. edu.

Skulmoski, G.J, Hartman F.T, Krahn J. 2007. "The Delphi method for graduate research". Journal of Information Technology Education. 6, 1-21.

Sofyan, Herminanto. 2011. Optimalisasi Pembelajaran Berbasis Kompetensi Pada Pendidikan Kejuruan. Jurnal Pendidikan Vokasi. Vol. 1, No. 1, hlm.113-131.

Sugiono.2009. Metode Penelitian Pendidikan (Pendekatan Kuantitatif, Kualitatif, dan $R \& D)$. Bandung. CV. Alfabeta.

The Conference Board of Canada. 2000. Employability Skills 2000+. Ottawa. http://www. conferenceboard.ca/nbec.

Thompson, J.F. 1973. Foundations of vocational education. New Jersey: Prentice-Hall, Inc.

Widiyanto. 2011. "Peranan Kompetensi Pekerja Terhadap Kebutuhan Industri Untuk Meningkatkan Daya Saing Perusahaan. Jurnal Pendidikan terakreditasi". Eksplanasi, Vol.6 No.1, Maret 2011, hlm.94-108. 